\title{
Restoration of alveolar type II cell function contributes to simvastatin-induced attenuation of lung ischemia-reperfusion injury
}

\author{
YAQIN WU ${ }^{1 *}$, JUNJIE LV $^{2 *}$, DONGJIE FENG ${ }^{1}$, FENG JIANG $^{1}$, \\ XIAOHU FAN ${ }^{3}$, ZHI ZHANG ${ }^{1}$, RONG YIN ${ }^{1}$ and LIN XU $^{1}$
}

\begin{abstract}
${ }^{1}$ Department of Thoracic Surgery, Nanjing Medical University Affiliated Cancer Hospital, Cancer Institute of Jiangsu Province, Nanjing 210009; ${ }^{2}$ Department of Thoracic Surgery, Huai'an First People's Hospital, Nanjing Medical University, Huai'an 223300, P.R. China; ${ }^{3}$ Department of Pediatrics, University of Alberta, Edmonton, Alberta T6E2E1, Canada
\end{abstract}

Received July 25, 2012; Accepted September 26, 2012

DOI: $10.3892 /$ ijmm.2012.1161

\begin{abstract}
Alveolar type (AT) II cells transdifferentiate into ATI cells and as such represent a promising source for regenerating lung epithelium following lung injury. ATII cells are characterized by the presence of lamellar bodies (LBs), which store and secrete the surfactant protein-C (SP-C). Lung ischemia-reperfusion injury (LIRI) causes a distinct impairment of the ATII cell function, subsequently hindering lung repair by loss of ATI transdifferentiation. In this study, we provide new evidence that the 3-hydroxy-3-methylglutaryl coenzyme A (HMG-CoA) reductase inhibitor simvastatin may restore the function of impaired ATII cells in vitro and in vivo. ATII cell lines, A549 (human) and MLE-12 (mouse), were subjected to hypoxia-reoxygenation (H/R) injury. Simvastatin pretreatment at low $(5-20 \mu \mathrm{M})$, but not high $(50-100 \mu \mathrm{M})$ doses markedly reduced apoptosis and increased proliferation and SP-C expression. In a rat lung ischemia-reperfusion (I/R) model, simvastatin treatment also increased ATII cell proliferation in vivo, as demonstrated by proliferating cell nuclear antigen/SP-C double staining. Transmission electron microscopy revealed that the number and volume density of LBs were significantly increased in the simvastatin-treated rat lungs. The protective effects of simvastatin were reversed in vitro by PI3-kinase (PI3K) inhibitors wortmannin and L-mevalonate, indicating that the PI3K/Akt and mevalonate pathways may be involved in simvastatin-induced ATII cell function restoration.
\end{abstract}

Correspondence to: Dr Rong Yin or Dr Lin Xu, Department of Thoracic Surgery, Nanjing Medical University Affiliated Cancer Hospital, Cancer Institute of Jiangsu Province, 42 Baiziting, Nanjing 210009, P.R. China

E-mail: yinhero001@126.com

E-mail: xulin_83@yahoo.cn

*Contributed equally

Key words: simvastatin, alveolar type II cells, lung ischemiareperfusion injury, proliferation, apoptosis
These data demonstrate that an appropriate dose of simvastatin has a protective effect on LIRI in vitro and in vivo, due at least partially to restored ATII cell function via the HMG-CoA reductase pathway-dependent activation of PI3K/Akt signaling in a mevalonate pathway-dependent manner.

\section{Introduction}

The lung alveolar epithelium covers $99 \%$ of the internal surface area of the lung and is composed of two morphological and functional distinct types of cells: alveolar type I (ATI) and type II (ATII). ATI cells have a broad flat shape, covering $95 \%$ of the alveolar surface and accounting for $40 \%$ of the alveolar epithelium and $8 \%$ of the peripheral lung cells. ATII cells, however, have a small cuboidal shape, covering only $5 \%$ of the alveolar surface and accounting for $60 \%$ of the alveolar epithelium and $15 \%$ of peripheral lung cells (1-3). ATII cells are also distinguished by the presence of lamellar bodies (LBs), intracellular organelles that store and secrete surfactant protein-C (SP-C). Functionally, ATII cells regulate alveolar fluid levels and contribute to host defense and the immune response $(4,5)$. Notably, accumulating evidence indicates that ATII cells are the progenitors of ATI cells in the alveoli; ATII cells are believed to play a pivotal role in maintaining tissue homeostasis via epithelium restoration $(1,3,6)$.

Once ATI cells become damaged by lung injury, ATII cells proliferate and transdifferentiate into ATI cells, thereby facilitating the repair of lung epithelium $(1,3,6)$. Transfusion of exogenous ATII cells derived from human embryonic stem cells was reported to efficiently repair acute lung injury in a mouse model (7). Using a rat lung ischemia-reperfusion injury (LIRI) model, we also discovered that ATII cells displayed a self-repair capacity. However, the process was protracted and insufficient (8). Therefore, research efforts are focused on developing methods to endogenously enhance the repair capacity of ATII cells or exogenously increase ATII cells $(1,3)$.

Statins, 3-hydroxy-3-methylglutaryl coenzyme A (HMG-CoA) reductase inhibitors, were initially developed as antimicrobials but quickly gained popularity for their efficacious lipid-lowering effects. Their widespread 
clinical use as first-line drugs for hyperlipidemia revealed potential pleiotropic pharmacological effects, and extensive research studies have demonstrated that the statins elicit antiinflammatory and angiogenic effects and improve vascular endothelial cell functions $(9,10)$. The HMG-CoA reductase pathway (also known as the mevalonate pathway) is essential for the synthesis of a number of isoprenoids, such as the prenylation-inducing farnesyl pyrophosphate and geranylgeranyl pyrophosphate, and mevalonate pathway-derived isoprenylation (and associated membrane localization) is a prerequisite for ligand-induced activation of several proteins. Since statins are able to inhibit HMG-CoA conversion to mevalonate, the pleiotropic effects of statins are usually mevalonate pathway-dependent (11). In addition, statin-induced inhibition of the mevalonate pathway may lead to the activation of the phosphatidylinositol-3 kinase (PI3K)/Akt pathway, which tightly controls cell fate processes, including proliferation and apoptosis and has been proposed as a mechanism of the protective effects of statin (12).

In terms of lung injury, Naidu et al (13) were the first to demonstrate that simvastatin was able to ameliorate LIRI and determined that the mechanism involved a modulation of the endothelial nitric oxide synthase (eNOS). Müller et al (14) later reported that high-dose simvastatin was able to attenuate ventilator-induced injury in mice by reducing pulmonary inflammation and hyperpermeability. However, clinical trials have not yet completely confirmed the protective effects of statins in lung injury. One trial discovered that statins had no influence on the progression of lung injury (15), but two others reported that statins improved organ dysfunction in acute lung injury (16) and decreased the lipopolysaccharideinduced pulmonary inflammation in healthy volunteers (17). Therefore, research to comprehensively elucidate under what conditions and by what mechanisms statins attenuate acute lung injury is required. Recently, simvastatin was shown to improve lung function by improving alveolar epithelial cell proliferation in a chronic obstructive pulmonary disease mouse model (18). We, therefore, hypothesized that simvastatin may also enhance the proliferation of ATII cells, which repairs the lung epithelium and thereby attenuates LIRI.

In this study, we demonstrated that simvastatin restores the function of impaired ATII cells both in vitro and in vivo, by using ATII cell lines (human A549 and mouse MLE-12) and a rat LIRI model, respectively. The data revealed that the restoration of ATII cell function involves the activation of PI3K/Akt signaling in a mevalonate pathway-dependent manner.

\section{Materials and methods}

Cell culture and the hypoxia-reoxygenation $(H / R)$ injury model. The human alveolar epithelium-derived type II cell line A549 (CCL-185) and mouse lung epithelial type II cell line MLE-12 (CRL-2110) were obtained from the American Type Culture Collection (ATCC, Manassas, VA, USA). The cells were respectively cultured in RPMI-1640 (Hyclone) and DMEM/F-12 media (Sigma-Aldrich, St. Louis, MO, USA) supplemented with $10 \%$ fetal bovine serum (FBS; Invitrogen Life Technologies), penicillin $(100 \mathrm{U} / \mathrm{ml})$ and streptomycin $(10 \mu \mathrm{g} / \mathrm{ml})$ in a humidified atmosphere of $5 \% \mathrm{CO}_{2}$ at $37^{\circ} \mathrm{C}$.
Logarithmically growing cells were seeded at a density of $5 \times 10^{4}$ cells $/ \mathrm{ml}$ for the following experiments. A hypoxic condition was created by incubating cells in a hypoxia chamber (Billups-Rothenberg, Del Mar, CA, USA) with an atmosphere of $95 \% \mathrm{~N}_{2} / 5 \% \mathrm{CO}_{2}$ at $37^{\circ} \mathrm{C}$ for $2 \mathrm{~h}$ for each cell group.

Cell proliferation assay. Cell proliferation was determined using the Cell Counting Kit-8 (CCK-8; Dojindo, Kumamoto, Japan) assay according to the manufacturer's protocol. Cells were suspended at a final concentration of $5 \times 10^{3}$ cells/well and cultured in 96-well flat bottom tissue culture plates. Cells were randomly divided into 7 groups, including the control and 6 simvastatin (Sigma-Aldrich) treatment groups $(5,10,20$, $30,50$ and $100 \mu \mathrm{mol} / \mathrm{l})$. Cells were pretreated with simvastatin for $30 \mathrm{~min}$ prior to incubation in hypoxic conditions. The proliferation assay was performed at $0,2,4,6,12$ and $24 \mathrm{~h}$ after reoxygenation. The proliferation ability of cells was evaluated by absorbance measurements at $450 \mathrm{~nm}$ using an automated microplate reader (CliniBio 128C; Tecan, Grödig, Austria). Final data from each cell group were normalized by subtracting the absorbance values of the blank group (cells without any treatment) and the experiments were performed in triplicates/group for each time point.

Flow cytometry. The ratio of apoptotic cells to SP-C-positive ATII cells was determined by flow cytometry (FACSCalibur; BD Biosciences, Franklin Lakes, NJ, USA) according to the manufacturer's instructions. Cells were suspended at a final concentration of $3 \times 10^{5}$ cells/well and cultured in 6-well flat bottom tissue culture plates. Cells were randomly divided into 6 groups including the control (H/R injury only) and 4 simvastatin treatment groups $(5,10,20$ and $50 \mu \mathrm{mol} / \mathrm{l})$. For apoptosis assay, cells were harvested at $4 \mathrm{~h}$ after reoxygenation and analyzed by Annexin V (AV), propidium iodide (PI) and an apoptosis detection kit (BD Biosciences). For detecting SP-C-positive ATII cells, cells were harvested at $24 \mathrm{~h}$ after reoxygenation and immunoreacted with primary antibody rabbit polyclonal anti-SP-C and secondary antibody Cy-3-labeled goat anti-rabbit IgG (Santa Cruz Biotechnology, Inc., Santa Cruz, CA, USA).

Animals and experimental design. Male Sprague-Dawley rats were obtained from the Laboratory Animal Center of Zhejiang Province (Hangzhou, China). All animals received human care in compliance with The Principles of Laboratory Animal Care, formulated by the National Society of Medical Research and Guide for the Care and Use of Laboratory Animals, published by the US National Institutes of Health (Publication no. 85-23, revised 1996). The experimental protocol was approved by the Animal Care and Scientific Committee of Nanjing Medical University. The animals were randomly divided into 4 groups $(n=6$ for each group at each time point): sham (no hilar clamping); I/R (left hilar clamping only); LSIM (orally treated with a low dose of $0.5 \mathrm{mg} / \mathrm{kg} /$ day simvastatin for 3 days prior to surgery and until the end of the experiments); HSIM (high dose of $5 \mathrm{mg} / \mathrm{kg} /$ day simvastatin, same schedule as LSIM). The rat LIRI model was established as previously described (8). Briefly, animals of the I/R group underwent warm ischemia for $60 \mathrm{~min}$ by left pulmonary hilar 
occlusion. Animals of the sham group underwent identical procedures without left pulmonary hilar occlusion. All animals of the 4 groups were sacrificed at baseline and $4 \mathrm{~h}$ and 3 days after reperfusion.

Lung injury evaluation. Lung injury was evaluated by hematoxylin and eosin (H\&E) staining and myeloperoxidase (MPO) activity assay. The specimens of the upper portion of the left lung were fixed in normal $4 \%$ buffered formalin for $48 \mathrm{~h}$, followed by dehydration in an ascending series of alcohol and embedded in paraffin wax. Sections $(\sim 4 \mu \mathrm{m})$ were stained with H\&E. Neutrophil infiltration and other inflammatory changes were examined in detail under light microscopy. MPO activity assay was used to compare the relative neutrophil sequestration in lung tissue of the experimental animals as previously described (8). Lung tissue MPO activity was expressed as the change in absorbance/g of protein/min.

Harvest of bronchoalveolar lavage (BAL) fluid. At the end of each experiment, BAL fluid was obtained by cannulating the trachea with a blunt 20-gauge needle and lavaging the lungs 3 times with $1 \mathrm{ml}$ of ice-cold PBS. The BAL was immediately centrifuged at $1000 \mathrm{rpm}$ for $15 \mathrm{~min}$ to remove all cells and cellular debris. The supernatant was stored at $-80^{\circ} \mathrm{C}$ until the protein concentrations were measured.

Double immunofluorescence staining. The left lung of each rat was collected and embedded in paraffin. Specimens were cut into $4-\mu \mathrm{m}$ serial sections, incubated overnight at $50^{\circ} \mathrm{C}$ and double stained for SP-C and proliferating cell nuclear antigen immunofluorescence. FITC-labeled goat anti-mouse IgG and Cy-3-labeled goat anti-rabbit IgG were employed as secondary antibodies for SP-C (rabbit polyclonal anti-SP-C; Santa Cruz Biotechnology, Inc.) and proliferating cell nuclear antigen (mouse monoclonal anti-PCNA; Abcam), respectively. Sections were examined using a Leica microscope equipped with a reflected light fluorescence device. Positively stained cells were counted by an investigator in a blinded manner. The number of positive cells was determined in 6 random areas in a high magnification field (x400)/section.

Ultrastructural analysis. At the end of each experiment, the lower portion of the left lung $\left(1 \mathrm{~mm}^{3}\right)$ was collected and fixed in $2.5 \%$ glutaraldehyde for $>12 \mathrm{~h}$ before processing for transmission electron microscopy (TEM). After primary fixation, pieces of each section were washed in $0.1 \mathrm{M}$ cacodylate buffer, postfixed in $1 \%$ osmium tetroxide $\left(\mathrm{OsO}_{4}\right)$ in buffer for $1 \mathrm{~h}$, washed in buffer, dehydrated through an ascending acetone series and flat-embedded in Epon-Araldite. Thin sections were cut from at least 3 blocks of embedded lungs/ animal using a Reichert UM 2 Ultramicrotome. The sections were mounted onto copper grids and stained using 5\% uranyl acetate and Reynold's lead citrate. They were examined using a Joel 1010 microscope at x10,000 magnification and operated at $80 \mathrm{kV}$; images were captured for ultrastructural analysis.

Stereological analysis. Stereological analysis does not involve assumptions and therefore fulfills the criteria for design-based or unbiased stereology. Following systematic uniformly random sampling on ultrathin sections, 10 ATII cells/section at x10,000 magnification were randomly identified under TEM. Digital micrographs of these cells subsequently underwent stereological analysis utilizing an image analysis system (AnalySIS; Soft Imaging System, Germany) as previously described (8). The morphometric parameters of LBs included volume density (Vv-LB), surface area density (Sv-LB), surface area and volume ratio (Rsv-LB) and number density (Nv-LB). Each parameter was calculated based on previously described formulas (8).

Western blot analysis. Cells, tissue specimens and BAL fluid were harvested and incubated for $10 \mathrm{~min}$ on ice with lysis buffer. The lysates were then centrifuged at $15,000 \mathrm{rpm}$ for $15 \mathrm{~min}$ at $4^{\circ} \mathrm{C}$ and the supernatants were collected. Protein concentration in the lysates was measured using a Beckman DU 800 Protein Assay kit (Thermo Fisher Scientific, Waltham, MA, USA). Equal amounts of protein samples were separated by sodium dodecyl sulfate-polyacrylamide gel electrophoresis (SDS-PAGE) and then transferred onto a polyvinylidene difluoride membrane (Millipore). Nonspecific binding sites were blocked in $5 \%$ non-fat milk and $0.1 \%$ Tween-20 in TBS for overnight shaking at $4^{\circ} \mathrm{C}$. The membranes were then incubated in a primary antibody buffer overnight, with gentle shaking at $4^{\circ} \mathrm{C}$ followed by 3 washes in $0.1 \%$ TBST, after which they were incubated with HRP-labeled secondary antibodies at room temperature for $2 \mathrm{~h}$ and again washed 3 times. The blots were then detected using SuperSignal West Pico Chemiluminescent Substrate ECL (Pierce Biotechnology, Inc. Thermo Fisher Scientific). The primary antibodies against SP-C and tubulin were purchased from Santa Cruz Biotechnology, Inc. PI3K/Akt signal pathway-related protein (Akt, phosphorylated(p)-Akt, P70, p-P70, mTOR, caspase-3) antibodies were purchased from Cell Signaling Technology, Inc. (Beverly, MA, USA). Protein density on scanned western blots was analyzed using Image J 1.44 software, and we performed semi-quantitative analysis for the results of the western blot analysis.

Statistical analysis. All data are represented as the means \pm SD. Data were analyzed using a commercially available statistical software package (SPSS for Windows, version 13.0; Chicago, IL, USA). The one-way analysis of variance (ANOVA) was used to analyze all the results statistically. Post hoc comparisons were performed using the Tukey's test or Dunnett's T3 test. A P-value of $<0.05$ was considered to indicate a statistically significant difference.

\section{Results}

Only low dose simvastatin improves the proliferation and inhibits the apoptosis of ATII cell lines after H/R injury. In order to evaluate whether simvastatin protects $H / R$-injured ATII cells, the CCK-8 Kit assay was used to determine cell proliferation at $0,2,4,6,12$ and $24 \mathrm{~h}$ after reoxygenation, and cell apoptosis was determined by AV/PI double-staining flow cytometry. Protein levels of SP-C at 4 and $24 \mathrm{~h}$ after reoxygenation were determined by western blot analysis. The ratio of SP-C-positive ATII cells at $24 \mathrm{~h}$ after reoxygenation was analyzed by flow cytometry. Only doses of simvastatin that were $<20 \mu \mathrm{M}$ increased the proliferation of ATII cells 

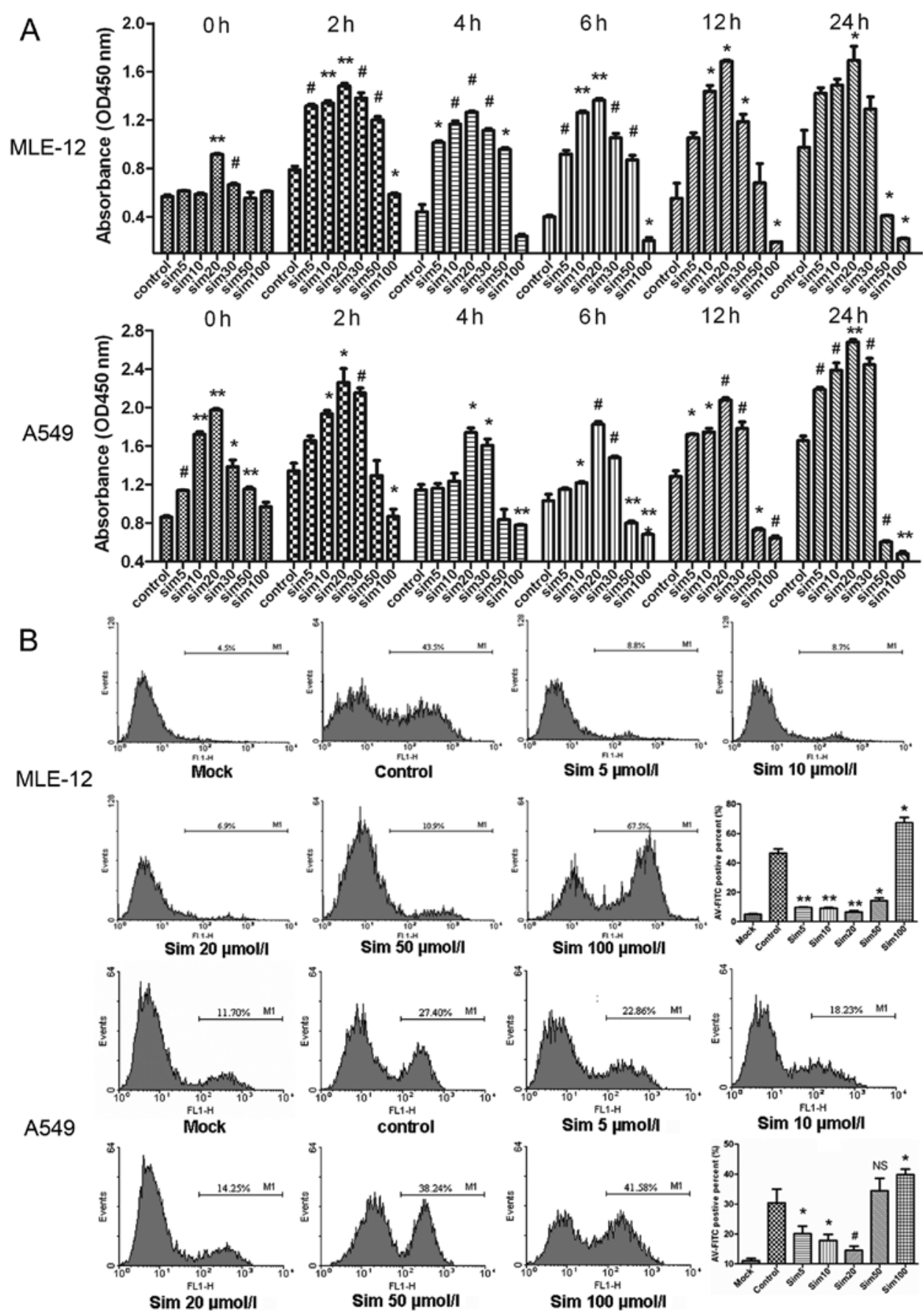

Figure 1. Biphasic effects of simvastatin on the proliferation and apoptosis of hypoxia-reoxygenation (H/R)-injured ATII cell lines. Results from MLE-12 (mouse) and A549 (human) ATII cell lines are presented. (A) Cell proliferation was determined using a CCK- 8 kit at the indicated times after reoxygenation. The proliferative capacity of ATII cells dose-dependently increased in response to low dose $(\leq 20 \mu \mathrm{M})$ simvastatin treatment, but deceased in response to high dose simvastatin (50 and $100 \mu \mathrm{M})$. (B) Cell apoptosis was determined by Annexin V and propidium iodide double-staining flow cytometry at $4 \mathrm{~h}$ after reoxygenation. Histograms of Annexin V (AV)-positive cells are presented, representing early and late apoptotic cells. The apoptotic cell ratios in the low dose simvastatin-treated groups $(5,10$ and $20 \mu \mathrm{M})$ were markedly lower compared to that in the control group. However, the ratio was significantly higher in high dose simvastatin-treated groups $(50$ and $100 \mu \mathrm{M})$. Data are expressed as the means \pm SD. Sim, simvastatin. ${ }^{*} \mathrm{P}<0.05,{ }^{\#} \mathrm{P}<0.01$ and ${ }^{* * *} \mathrm{P}<0.001$ vs. control group. NS, no significance.

and inhibited apoptosis. Both MLE-12 and A549 cells reacted similarly to the low dose simvastatin treatment (Fig. 1A). A response was noted by MLE-12 cells to $20 \mu \mathrm{M}$ simvastatin and by A549 cells starting at $5 \mu \mathrm{M}$ simvastatin with regards to proliferation at time 0 ; this may be due to the nature of different cell types. After reoxygenation in the control group, the proliferative capability was increased at $2 \mathrm{~h}$, slightly decreased at 4 and $6 \mathrm{~h}$ and increased at 12 and $24 \mathrm{~h}$. As compared with the control group, the low dose $(\leq 20 \mu \mathrm{M})$ simvastatin-treated groups exhibited dose-dependent increases in the proliferative capacity of ATII cells. It was notable that the ATII cells treated with $20 \mu \mathrm{M}$ simvastatin demonstrated statistically significant increases at all time points examined. High dose simvastatin $(50$ and $100 \mu \mathrm{M})$ treatments did not significantly increase the proliferative capacity of ATII cells at any of the time points examined. In fact, proliferation of 

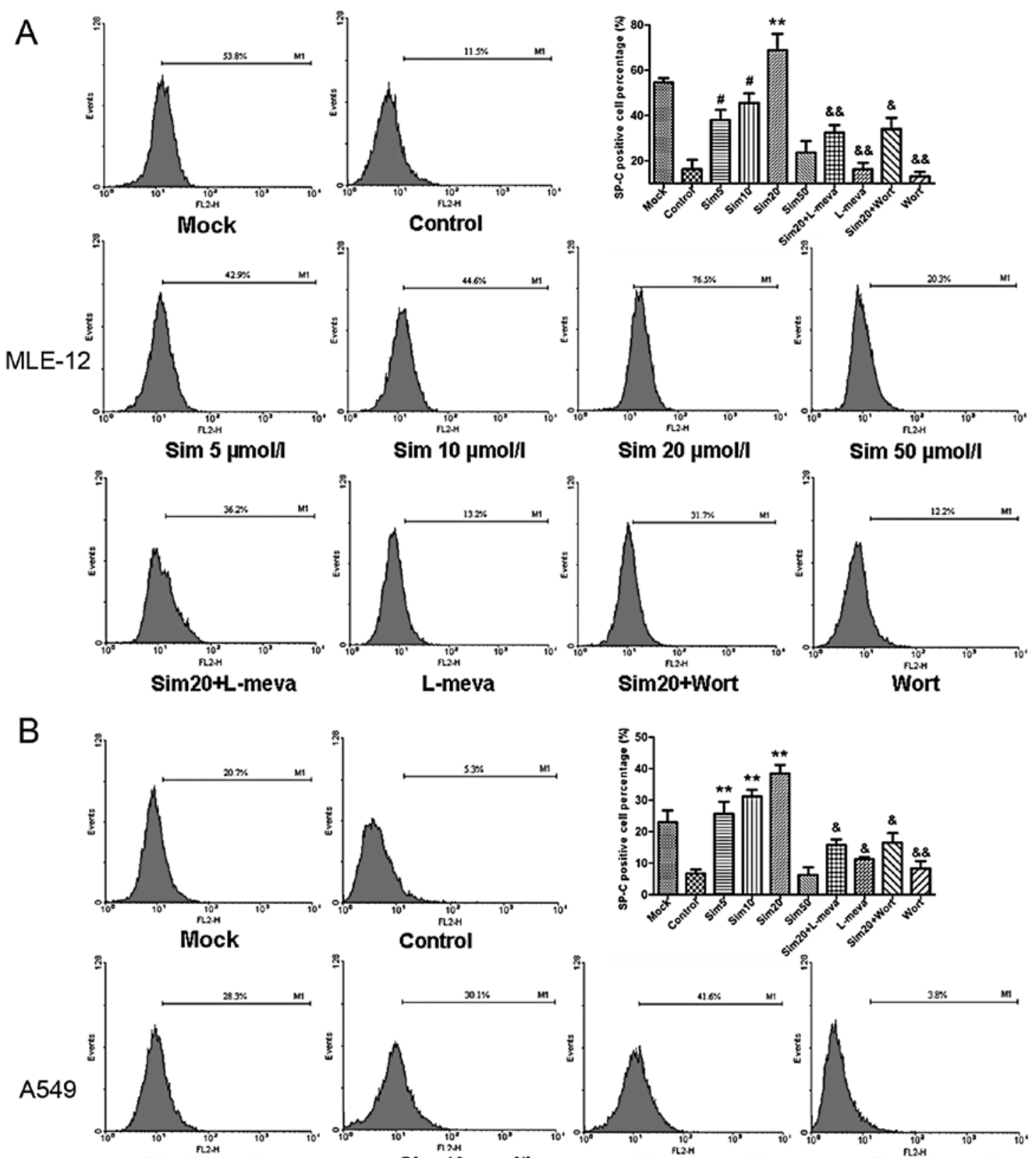

Sim 5 umolil

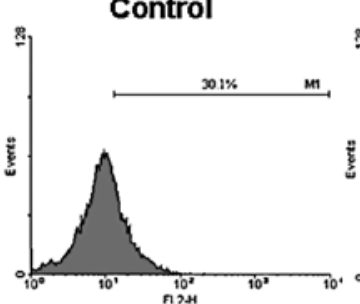

$\operatorname{Sim} 10 \mu \mathrm{mol} / \mathrm{I}$

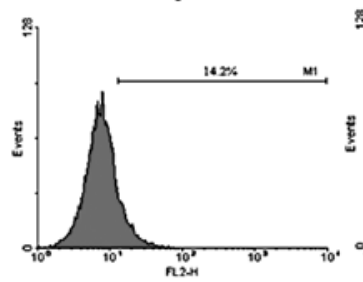

Sim20+L-meva

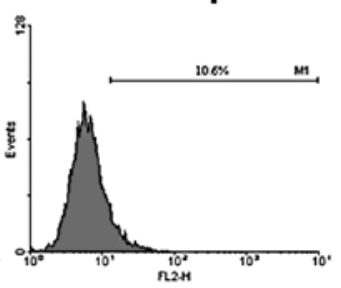

L-meva

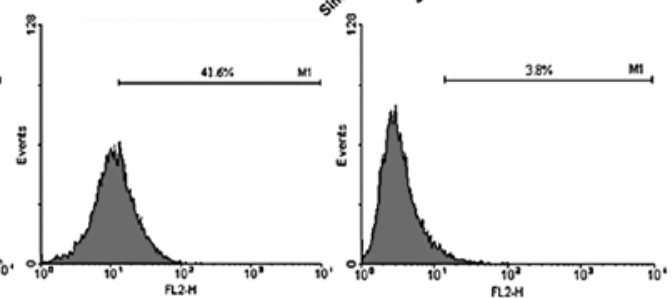

$\operatorname{Sim} 20 \mu \mathrm{mol} / \mathrm{I}$

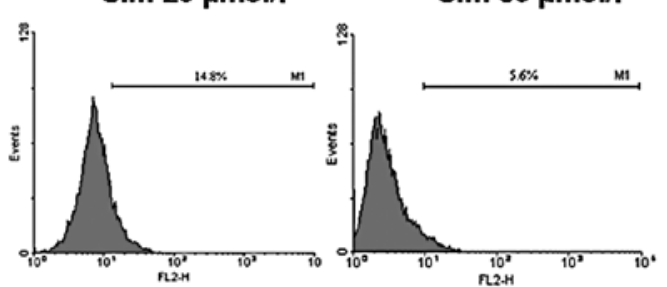

Sim20+Wort

Wort

Figure 2. Effects and mechanisms of simvastatin (sim) on the SP-C-positive cell ratio in hypoxia-reoxygenation (H/R)-injured ATII cell lines, MLE-12 (A) and A549 (B). SP-C-positive cell ratio was determined by flow cytometry at $24 \mathrm{~h}$ after reoxygenation. SP-C-positive cell percentage was significantly increased in low dose simvastatin-treated groups $(5,10$ and $20 \mu \mathrm{M})$, as compared with the control groups, whereas it was markedly decreased in the $50 \mu \mathrm{M}$ simvastatin-treated groups. Administration of L-mevalonate (L-meva, $20 \mu \mathrm{M}$ ) blocked the increasing SP-C-positive cell number by simvastatin by rescuing simvastatin-induced mevalonate depletion. Similarly, wortmannin (Wort), a competitive PI3K inhibitor, reversed the simvastatin-induced increase of the percentage of SP-C positive cells. Data are expressed as means \pm SD. ${ }^{*} \mathrm{P}<0.05,{ }^{\#} \mathrm{P}<0.01$ and ${ }^{* * *} \mathrm{P}<0.001$ vs. control group; ${ }^{\&} \mathrm{P}<0.05$, ${ }^{\text {\& }} \mathrm{P}<0.01$ vs. sim 20 group.

MLE-12 and A549 cells was significantly lower compared to that in the control groups at 12 and $24 \mathrm{~h}$ after reoxygenation, and the proliferation of A549 cells was markedly lower in response to the $100 \mu \mathrm{M}$ simvastatin treatment.
AV/PI double staining was used to identify cell apoptosis, which is presented as a histogram indication of FITC-AVpositive cells and includes both early and late apoptotic cells. Since our previous study demonstrated that the apoptosis of 
A
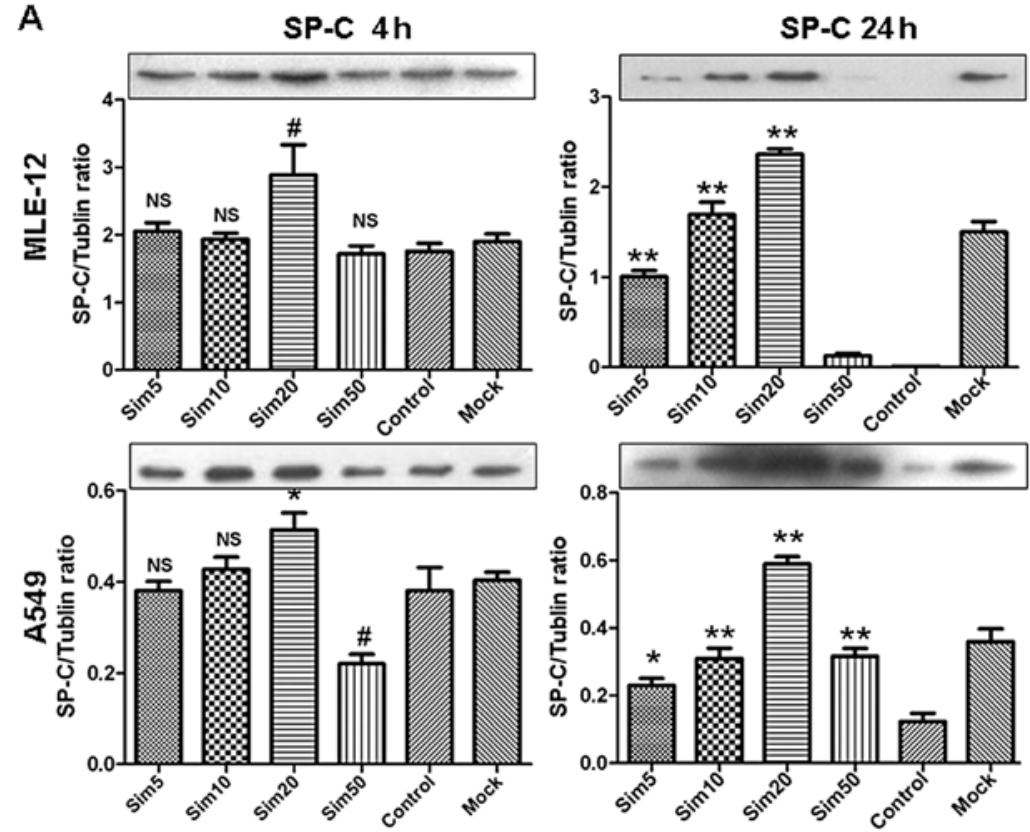

B

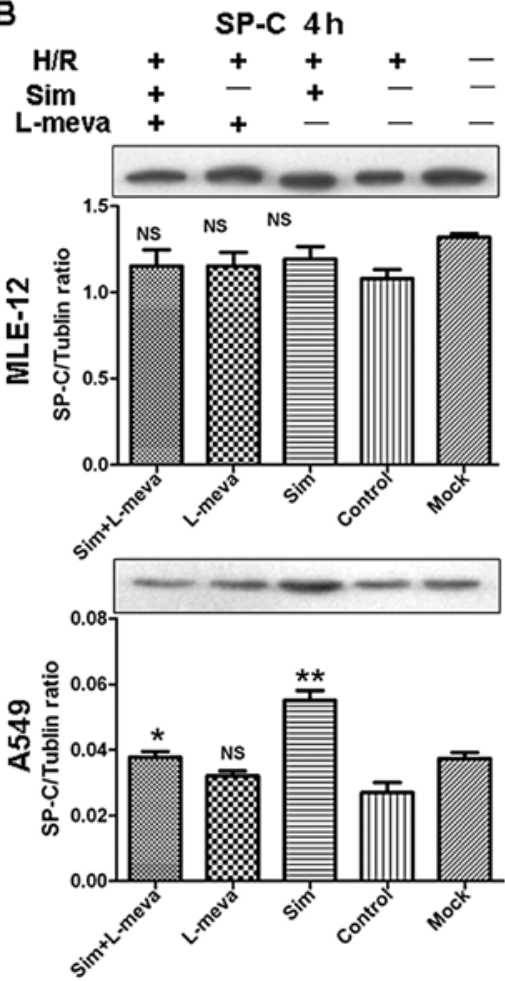

SP-C $24 \mathrm{~h}$

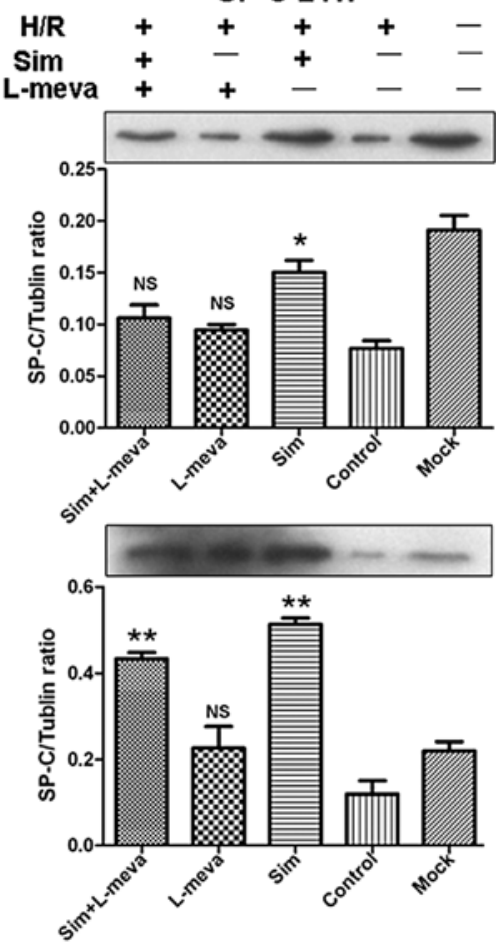

Figure 3. Effects and mechanisms of simvastatin on the surfactant protein-C (SP-C) protein levels in hypoxia-reoxygenation (H/R)-injured ATII cell lines, MLE-12 and A549. (A) SP-C protein levels at 4 and $24 \mathrm{~h}$ after reoxygenation were determined by western blot analysis and demonstrated an increase in response to low dose simvastatin treatment $(5,10$ and $20 \mu \mathrm{M})$, but a decrease in response to high dose treatment (50 and $100 \mu \mathrm{M})$. (B) Effects of L-mevalonate (L-meva) on the simvastatin-induced reduction in SP-C protein levels at 4 and $24 \mathrm{~h}$ after reoxygenation were determined by western blot analysis. Co-treatment with L-meva and simvastatin further reduced SP-C protein levels, as compared to the simvastatin-alone treatment group. ${ }^{*} \mathrm{P}<0.05$, ${ }^{\prime} \mathrm{P}<0.01$ and ${ }^{* *} \mathrm{P}<0.001$ vs. H/R group. NS, no significance.

ATII cells usually increases at $4 \mathrm{~h}$ after LIRI (8), we selected the $4 \mathrm{~h}$ time point after reoxygenation for the observations of cell apoptosis after H/R. For both MLE-12 and A549 cells the apoptotic cell ratio was markedly lower in the low dose simvastatin-treated groups $(5,10$ and $20 \mu \mathrm{M})$ compared to the control groups (Fig. 1B). In contrast, the apoptotic cell ratio in the high dose simvastatin-treated groups $(50$ and $100 \mu \mathrm{M})$ was significantly increased as compared with the low dose groups. The $100 \mu \mathrm{M}$ simvastatin-treated groups in both MLE-12 and A549 cells exhibited markedly increased numbers of apoptotic cells, up to $50 \%$ more than that in the control groups.

Finally, the simvastatin-induced changes in the percentage of SP-C-positive ATII cells and SP-C protein levels were detected (Figs. 2 and 3A, respectively). The MLE-12 and 
A

A

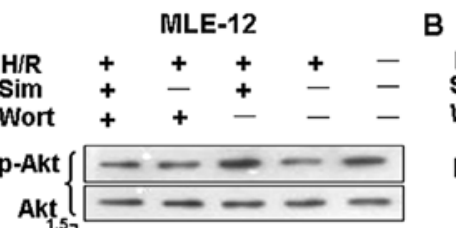

B

$\begin{array}{llllll}\mathbf{H} / R & + & + & + & + & - \\ \text { Wort } & + & + & + & - & -\end{array}$

p-Akt $\left\{\begin{array}{l}-\cdots-\cdots \\ \text { Akt }\end{array}\right.$

p-Akt $\{-\cdots-\cdots$

Akt 1.5 $=2$
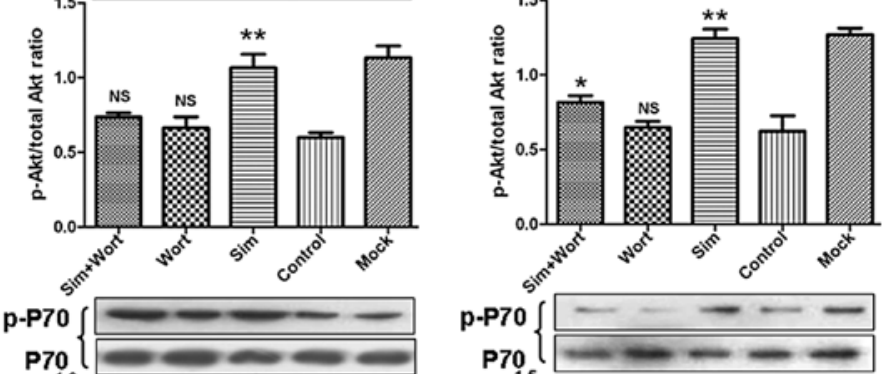

P70
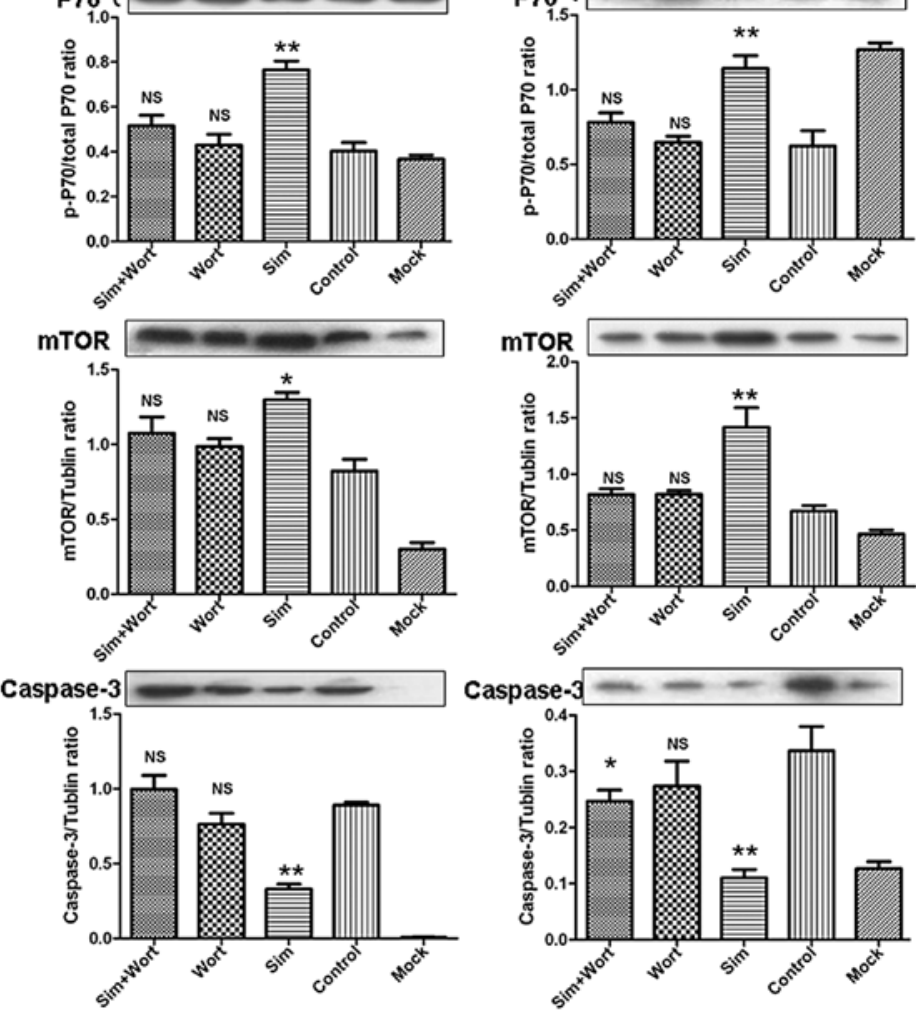

Caspase-3 $-\infty-2$
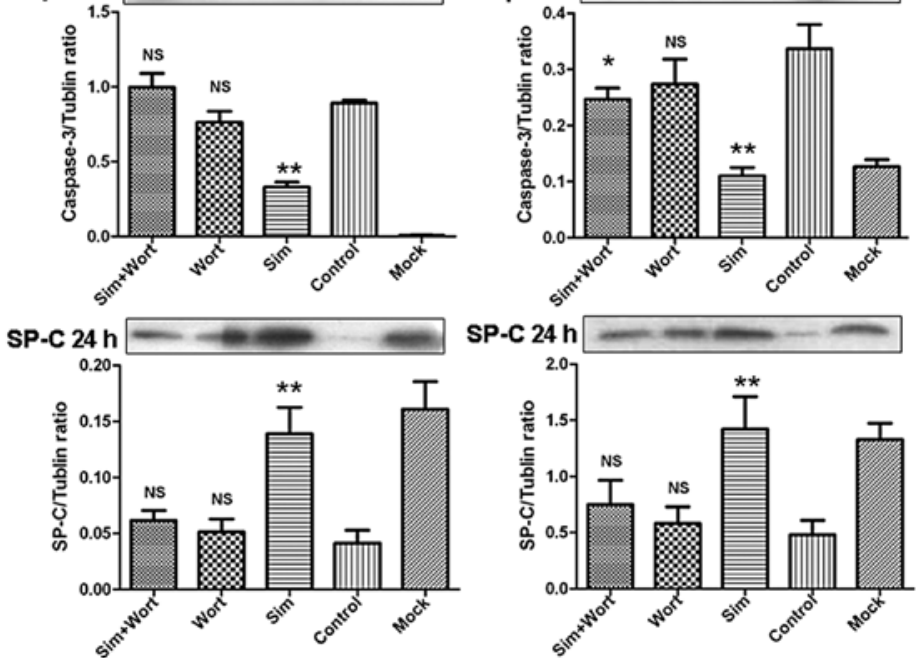

Figure 4. Effects and mechanisms of simvastatin on the PI3K/Akt pathway in hypoxia-reoxygenation (H/R)-injured ATII cell lines, (A) MLE-12 and (B) A549. Effects of the PI3K inhibitor, wortmannin (Wort) on the simvastatin-induced reduction of SP-C protein levels at 24 h after reoxygenation and on $\mathrm{PI} 3 \mathrm{~K} / \mathrm{Akt}$ signaling pathway-related proteins at $4 \mathrm{~h}$ after reoxygenation. The PI3K/Akt pathway was activated in the simvastatin-treated group, but this effect was reversed by Wort treatment. ${ }^{*} \mathrm{P}<0.05,{ }^{*} \mathrm{P}<0.01$ and ${ }^{* *} \mathrm{P}<0.001$ vs. H/R group. NS, no significance.

A549 cell lines again demonstrated similar trends in response to simvastatin treatments. At $4 \mathrm{~h}$ after reoxygenation, there was no significant difference observed in the percentage of SP-C-positive cells between the simvastatin-treated and the control groups (data not shown). This finding was consistent with the SP-C protein detected by western blot analysis (Fig. 3A). Furthermore, at $24 \mathrm{~h}$ after reoxygenation, the percentage of SP-C-positive cells was significantly increased in the low dose simvastatin-treated groups (5, 10 and $20 \mu \mathrm{M})$, compared with the control groups. In contrast, the percentage was markedly decreased in the $50 \mu \mathrm{M}$ simvastatin-treated groups, and was even lower than the control group for the A549 cell line. These results were confirmed by western blot analysis. 
A

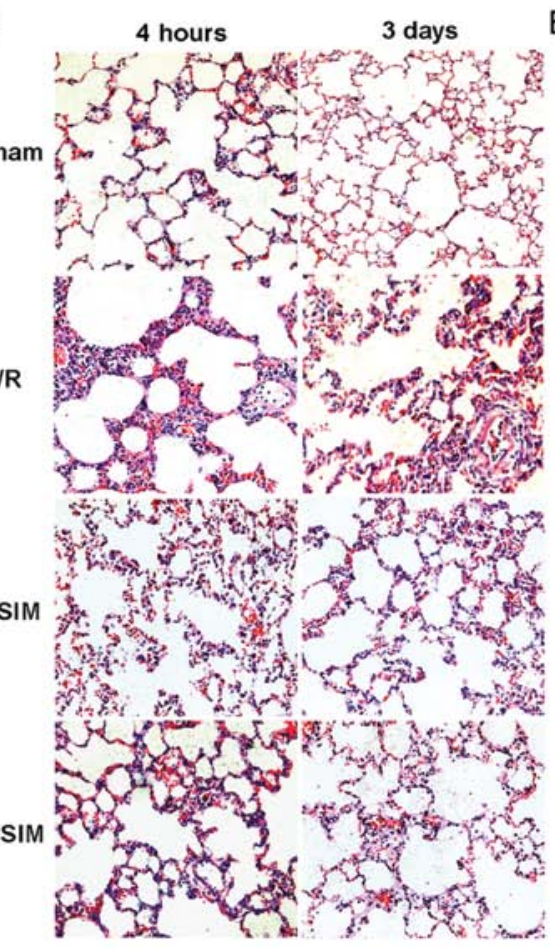

Hematoxylin-Eosin staining

B 4 hours 3 days

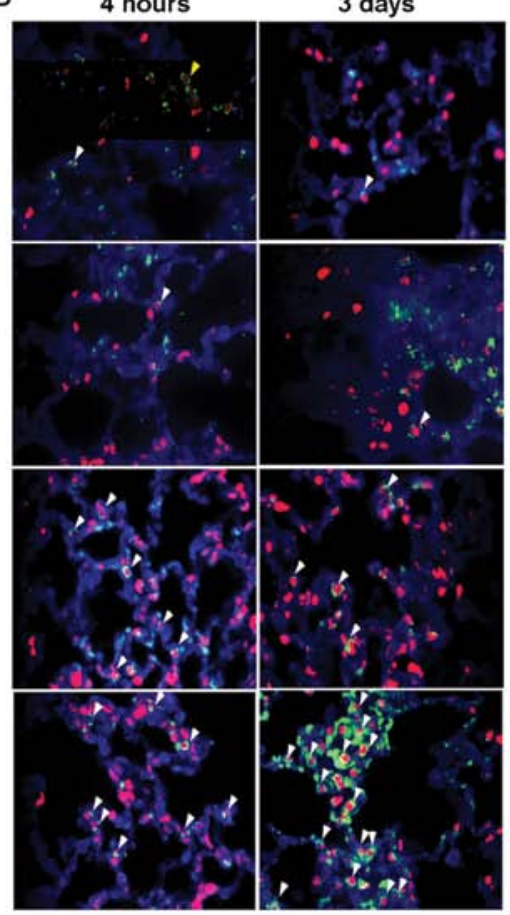

SP-C/PCNA double staining

C
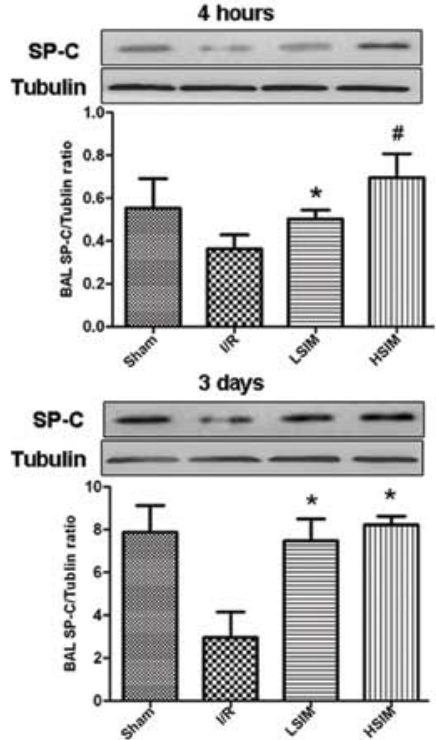

E
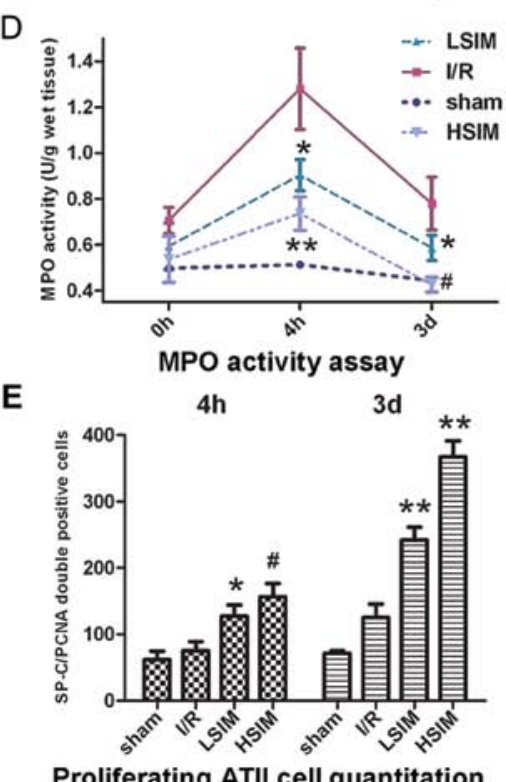

BAL SP-C protein levels

Figure 5. Effects of simvastatin on a rat model of lung ischemia-reperfusion injury (LIRI). LIRI was evaluated by hematoxylin and eosin (H\&E) staining. SP-C levels in bronchoalveolar lavage (BAL) fluid were determined and myeloperoxidase (MPO) activity assay was carried out. Proliferation of ATII cells in rat lung tissues was indicated by immunofluorescence double staining of SP-C and PCNA. (A) Representative images of H\&E staining in each group at $4 \mathrm{~h}$ and 3 days after reperfusion are shown (original magnification x200). (B) Representative images of SP-C (FITC-labeled green) and PCNA (Cy3-labeled red) immunofluorescence double staining are shown (original magnification $\mathrm{x} 400$ ). (C) SP-C protein levels in rat BAL fluid were determined by western blot analysis and were significantly increased in the simvastatin-treated groups at $4 \mathrm{~h}$ and 3 days after reperfusion, as compared with the I/R group. (D) MPO activity in rat lung tissues was significantly attenuated in the simvastatin-treated groups at $4 \mathrm{~h}$ and 3 days after reperfusion, as compared with the $\mathrm{I} / \mathrm{R}$ group. (E) Quantitative analysis of SP-C/PCNA double-positive cells revealed that the number of proliferative ATII cells was significantly increased in the simvastatin-treated groups at $4 \mathrm{~h}$ and 3 days after reperfusion, as compared with the I/R group. LSIM, low dose simvastatin (0.5 mg/kg/day) group; HSIM, high dose simvastatin $\left(5 \mathrm{mg} / \mathrm{kg} /\right.$ day) group. ${ }^{*} \mathrm{P}<0.05,{ }^{, \mathrm{P}}<0.01$ and ${ }^{* *} \mathrm{P}<0.001$ vs. $\mathrm{I} / \mathrm{R}$ group. NS, no significance.

Restoration of ATII cell function in vitro by low dose simvastatin is mediated by the mevalonate and the PI3K/Akt signaling pathways. In order to investigate whether the mevalonate pathway and the downstream PI3K/Akt pathway are involved in the restoration of ATII cell function induced by statins, L-mevalonate (L-meva) and wortmannin (Wort) were used in the following experiments. L-meva restores mevalonate depletion induced by simvastatin and Wort is a competitive inhibitor of the PI3K protein. Administration of L-meva $(20 \mu \mathrm{M})$ significantly blocked the SP-C-increasing effect of simvastatin by rescuing simvastatin-induced mevalonate depletion in the MLE-12- and A549-treated cells, as 


\section{A \\ Sham}
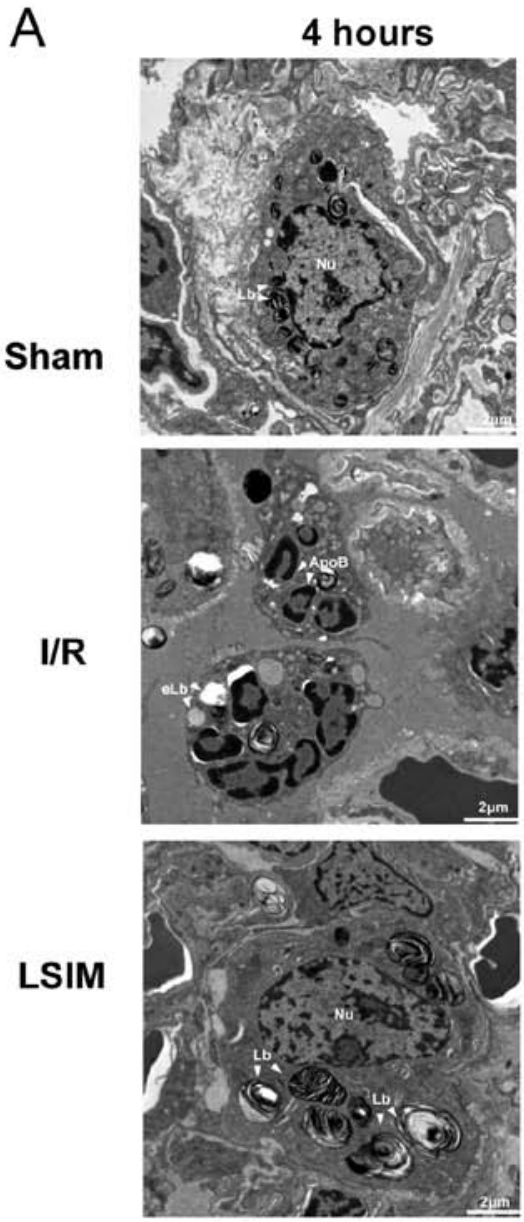

HSIM

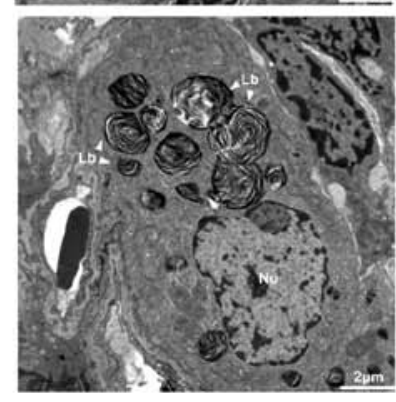

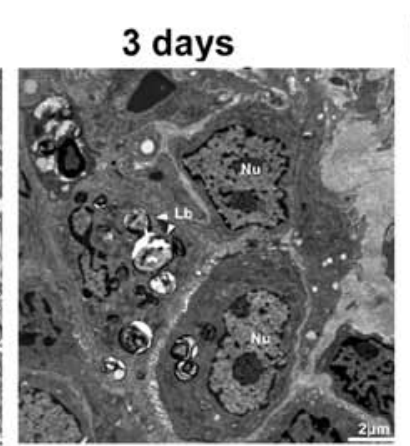

B
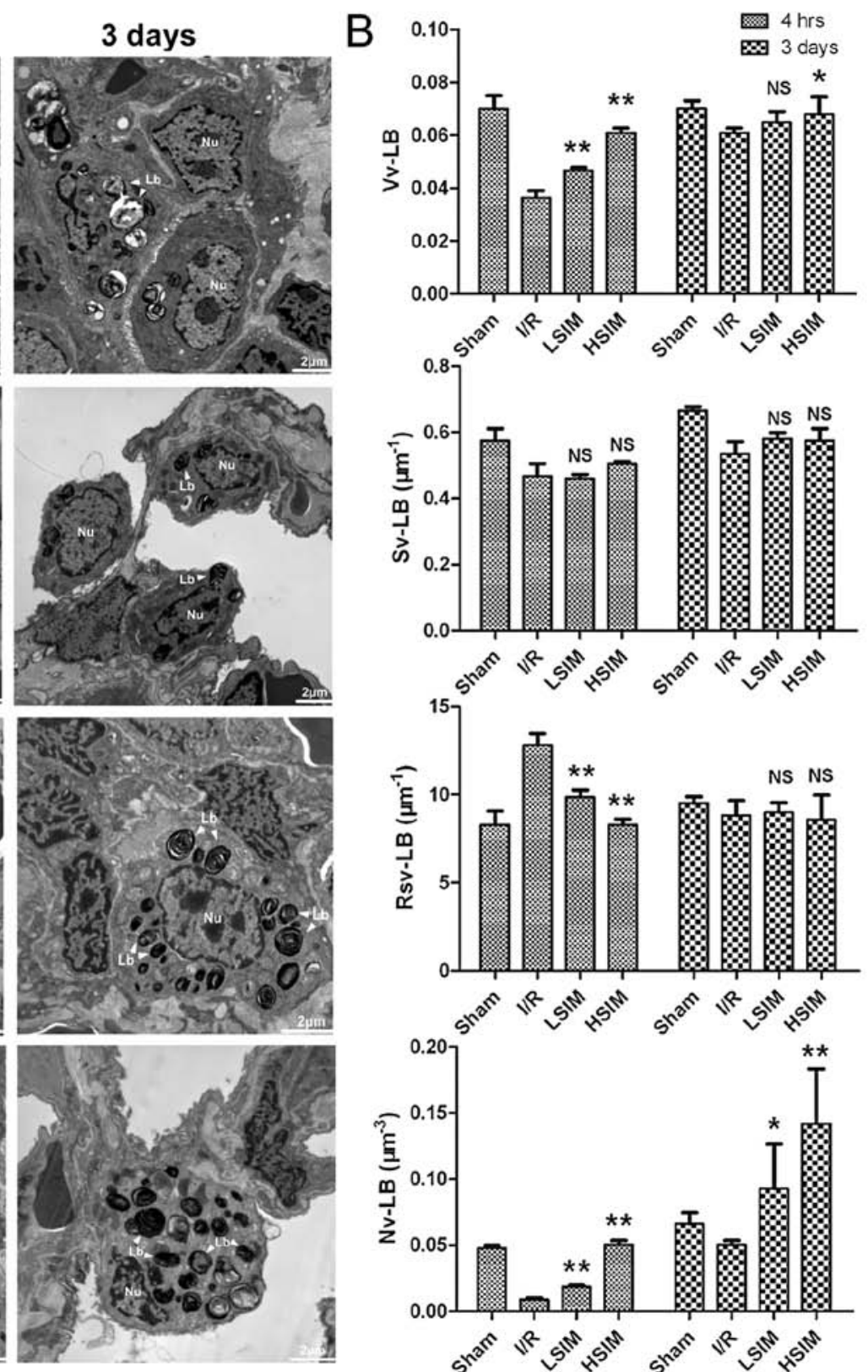
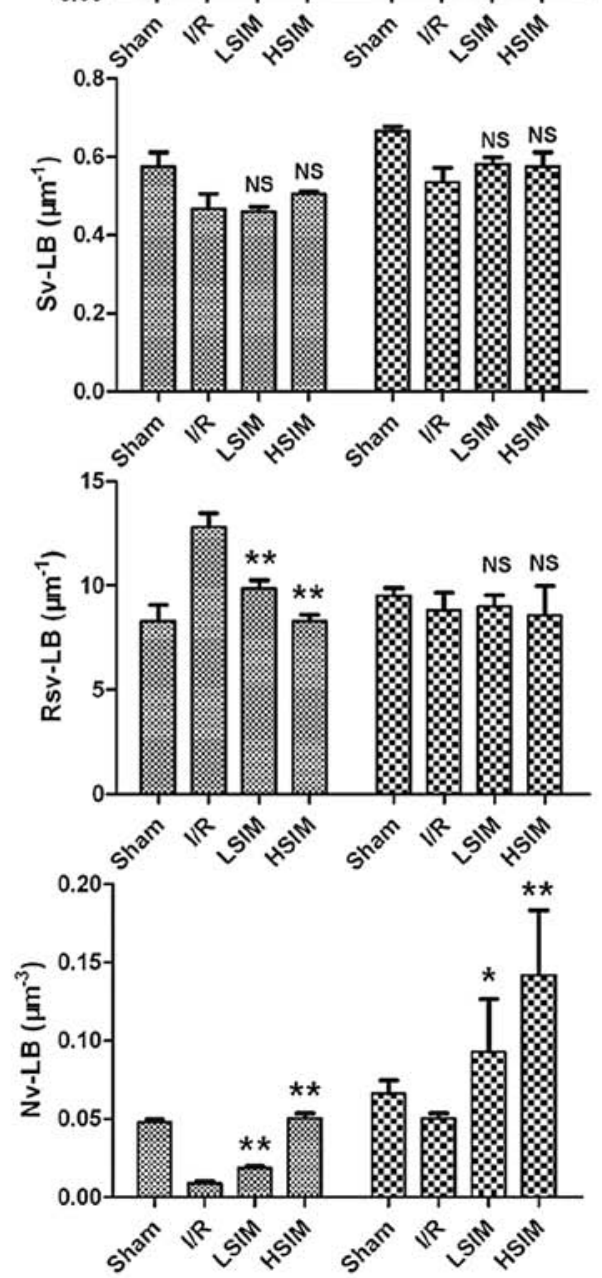

Figure 6. Transmission electron microscopy of the ultrastructure of ATII cells in rat lung tissues. TEM images were obtained under magnification x10,000. (A) Representative ultrastructural images of ATII cells in each group at $4 \mathrm{~h}$ and 3 days after I/R injury. (B) Stereological analysis of lamellar bodies in ATII cells from each group. The morphometric parameters of lamellar bodies included volume density ( $\mathrm{Vv}$-LB), surface area density (Sv-LB), surface area and volume ratio (Rsv-LB) and number density (Nv-LB). Both the Vv-LB and Nv-LB were found to be significantly increased in the simvastatin-treated groups. eLb, empty lamellar bodies; LB, lamellar bodies; Nu, nucleus; ApoB, apoptotic bodies; I/R, ischemia-reperfusion group; LSIM, low dose simvastatin $\left(0.5 \mathrm{mg} / \mathrm{kg} /\right.$ day) group; HSIM, high dose simvastatin $\left(5 \mathrm{mg} / \mathrm{kg} /\right.$ day) group. ${ }^{*} \mathrm{P}<0.05$ and ${ }^{* *} \mathrm{P}<0.001 \mathrm{vs}$. I/R group. NS, no significance.

compared to the simvastatin only treated groups at $24 \mathrm{~h}$ after reoxygenation (Figs. 2 and 3B). Similarly, treatment with Wort $(100 \mathrm{nM})$ in combination with simvastatin reversed the simvastatin-induced increase in the percentage of SPC-positive cells and the SP-C protein levels at $24 \mathrm{~h}$ after reoxygenation in both cell lines (Figs. 2 and 4). Moreover, cells treated with $20 \mu \mathrm{M}$ simvastatin showed increased levels of $\mathrm{p}$-Akt and downstream p-P70 and m-TOR and suppressed caspase-3 levels at $4 \mathrm{~h}$ after reoxygenation (Fig. 4). Co-administration of Wort and simvastatin resulted in markedly suppressed p-Akt levels leading to observed decreases in m-TOR and P70 levels, as well as to the downstream increases in caspase-3 levels.
Simvastatin dose-dependently attenuates the LIRI, promotes proliferation of ATII cells and restores their function in vivo. To evaluate the protective effect of simvastatin on LIRI, H\&E staining and MPO activity assay were performed on rat lung tissues. As shown in Fig. 5A, serious LIRI was achieved in the $\mathrm{I} / \mathrm{R}$ group, as evidenced by infiltration of neutrophils and small areas of intra-alveolar edema at $4 \mathrm{~h}$ after reperfusion, which slightly recovered 3 days after reperfusion. In the simvastatintreated groups, less neutrophil infiltration was observed and the areas of intra-alveolar edema were less than that in the I/R group. In the HSIM group, the pulmonary structure was found to be mostly recovered to normal 3 days after reperfusion. 

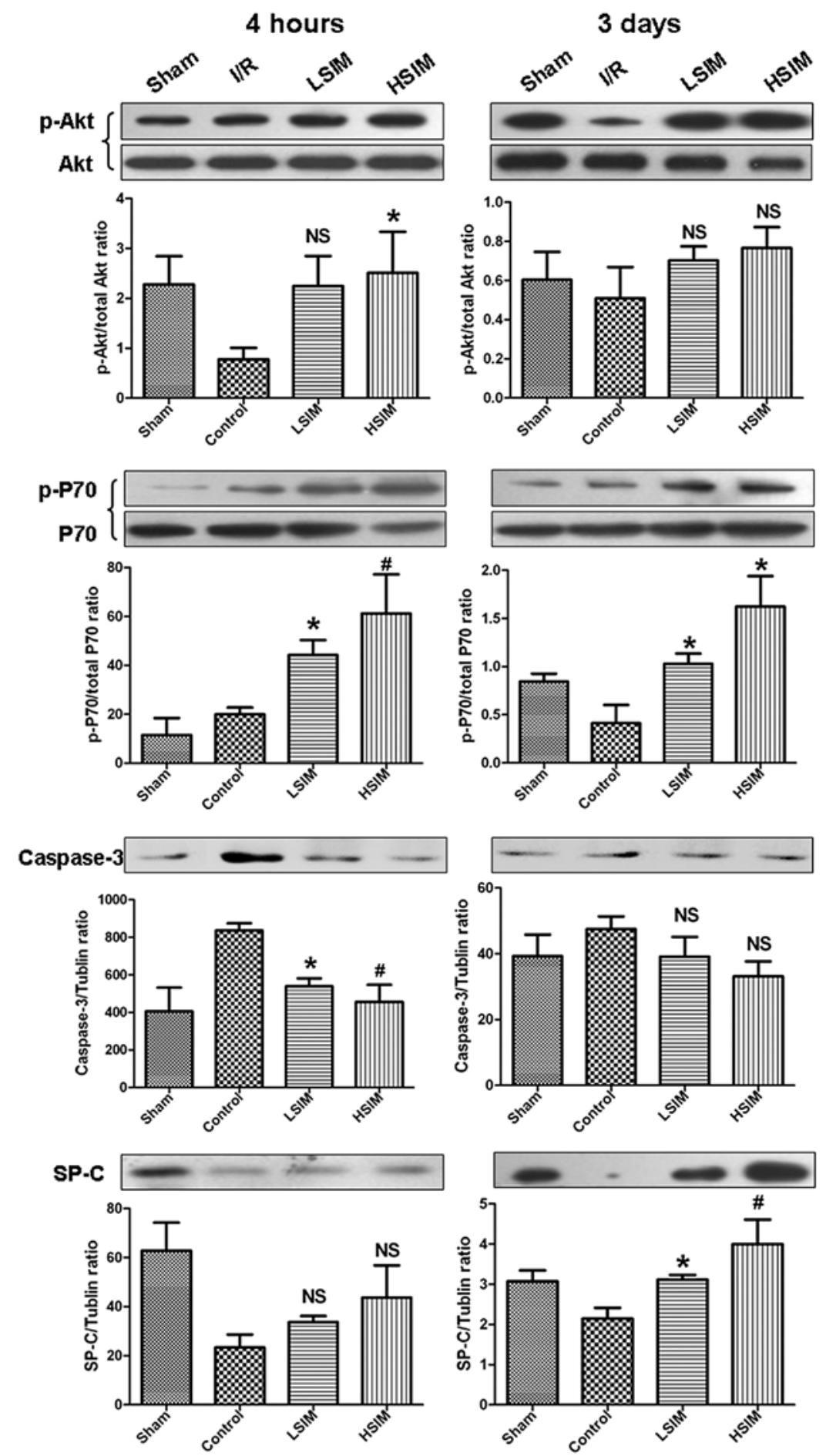

Figure 7. In vivo effects of simvastatin on PI3K/Akt signaling pathway-related protein levels in rat lung tissues. Western blot analysis was used to measure the protein levels of phosphorylated-Akt, phosphorylated-P70, caspase-3 and SP-C at $4 \mathrm{~h}$ and 3 days after reperfusion. p-Akt and p-P70 levels were normalized to total Akt and P70, respectively. Other detected protein levels were normalized to tubulin. The PI3K/Akt pathway was activated in the simvastatin-treated groups. I/R, ischemia-reperfusion group; LSIM, low dose simvastatin ( $0.5 \mathrm{mg} / \mathrm{kg} /$ day) group; HSIM, high dose simvastatin ( $5 \mathrm{mg} / \mathrm{kg} / \mathrm{day})$ group. * $<0.05$ and ${ }^{\text {"}} \mathrm{P}<0.01$ vs. I/R group. NS, no significance.

The MPO activity assay confirmed the observations of H\&E staining (Fig. 5D). Compared with the baseline of the sham group, the MPO activities of the I/R group were elevated at $4 \mathrm{~h}$ and slightly declined at 3 days after reperfusion. However, the simvastatin-treated groups displayed significant and dosedependent decreases of MPO activities at both $4 \mathrm{~h}$ and 3 days after reperfusion, as compared with the I/R group.
Furthermore, SP-C protein levels in BAL fluid were determined and SP-C/PCNA double immunofluorescence staining of lung tissues was performed to evaluate the proliferation and function of ATII cells. In both LSIM and HSIM groups, SP-C protein levels in BAL fluid were significantly increased at $4 \mathrm{~h}$ and 3 days after reperfusion as compared with the I/R group. The FITC-SP-C and Cy-3-PCNA double-positive cells 
were counted in a high magnification field (x400). As shown by the representative images in Fig. 5B and the quantitative analysis in Fig. 5E, SP-C/PCNA double-positive cell numbers in the LSIM and HSIM groups were found to be significantly increased at $4 \mathrm{~h}$ and further increased (by $>2$-fold) at 3 days after reperfusion, as compared with the $\mathrm{I} / \mathrm{R}$ group.

Finally, ultrastructural examination and stereological analysis were performed to evaluate the function of ATII cells in the rat models. Representative images of the ultrastructural findings and stereological analysis results for each treatment group are shown in Fig. 6. The nuclei and LBs of ATII cells were found to be intact in the sham group at $4 \mathrm{~h}$ and 3 days after reperfusion (Fig. 6A). Apoptotic ATII cells were also present at $4 \mathrm{~h}$ after reperfusion. Numerous apoptotic bodies (ApoB), dilations of nuclear, scattered chromatin and empty LBs (eLBs) were observed. Gradual self-repair of ATII cells was observed until 3 days after reperfusion, and the number and volume of LBs remained low and small. However, in the LSIM and HSIM groups, the ApoB and eLB structures were markedly absent at $4 \mathrm{~h}$ after reperfusion and numerous LBs were noted at 3 days after reperfusion. The results of quantitative comparison by stereological analysis are shown in Fig. 6B. At $4 \mathrm{~h}$ after reperfusion, as compared with the I/R group, both the Vv-LB and Nv-LB were significantly higher in LSIM and HSIM groups. The Rsv-LB levels were markedly lower in LSIM and HSIM groups. In particular, at 3 days after reperfusion, the Nv-LB levels in LSIM and HSIM groups were drastically higher compared to those in the $\mathrm{I} / \mathrm{R}$ group ( 2- to 3-fold).

PI3K/Akt signaling pathway is involved in simvastatincontributing protective effects on ATII cells in vivo. In order to investigate whether the PI3K/Akt pathway is involved in the in vivo protective effects of statins, the relative levels of $\mathrm{PI} 3 \mathrm{~K} / \mathrm{Akt}$ signaling pathway-related proteins were determined by western blot analysis. At $4 \mathrm{~h}$ after reperfusion, $\mathrm{p}$-Akt levels in the LSIM and HSIM groups were significantly higher compared to the I/R group (Fig. 7). Subsequently, the downstream p-P70 level was also markedly increased. At 3 days after reperfusion, p-Akt levels further increased in the LSIM and HSIM groups, as did the downstream p-P70 levels. There appeared to be no difference in the caspase-3 level between each group; however, the SP-C levels in the LSIM and HSIM groups increased markedly.

\section{Discussion}

Although the protective effects of statins on LIRI have been investigated previously (13), to the best of our knowledge, our study is the first to provide evidence that lung ATII cells are the potential target of statin therapy in LIRI. First, our data demonstrated a biphasic effect of simvastatin on ATII cells in vitro. Only a low dose of simvastatin $(\leq 20 \mu \mathrm{M})$ improved proliferation and inhibited apoptosis of ATII cells, whereas a high dose of simvastatin ( $\geq 50 \mu \mathrm{M})$ promoted apoptosis. Second, the in vitro protective effects of simvastatin were observed to be reversed by L-meva and Wort, a competitive inhibitor of the PI3K pathway. Third, the in vivo rat LIRI model also demonstrated that the number of proliferative ATII cells was significantly increased and the number and volume density of their functional cell organelle LBs was dose-dependently enhanced by simvastatin. Thus, our results provide a new understanding of the mechanisms underlying statin-induced attenuation of LIRI and the facilitation of tissue repair, whereby the function of ATI progenitor cells, ATII cells, were restored by simvastatin via activation of the PI3K pathway in a mevalonate pathway-dependent manner. These findings provide further insights into the utility and mechanism of simvastatin treatment of LIRI, and may benefit future research into improved clinical applications of simvastatin.

During the past decades, several reports have been published on the pleiotropic effects of statins, involving various disease processes of different organs. Statins are well-recognized for their properties of lowering lipid content, protecting against IR injury $(19,20)$, quelling inflammation (21-24), improving tissue remodeling $(25,26)$, modulating angiogenesis (27), promoting cell proliferation (18), and inhibiting cancer cell proliferation and inducing apoptosis (28-32). However, nearly as many reports exist that present experimental data that contradict the protective effects of statins (15). In the present study, we also obtained contradictory results in that simvastatin produced biphasic effects on ATII cell proliferation and apoptosis according to the dose. Furthermore, we observed that a low dose of simvastatin $(20 \mu \mathrm{M})$ was able to activate PI3K/Akt signaling, which contradicts results from other studies that indicated that statins inhibit signaling of this pathway $(25,28-32)$. In order to better elucidate these paradoxical phenomena, we reviewed the results of several representative studies on the pleiotropic effects of statins.

Firstly, the dosage of statins may be an important factor that impacts their biological effects. Previous investigations have reported findings of dose-dependent biphasic effects of statins on tissue angiogenesis. Weis et al (27) demonstrated that low concentrations of statins $(0.005-0.01 \mu \mathrm{M})$ enhanced endothelial cell (EC) proliferation, migration and differentiation, which were significantly inhibited by high concentrations $(0.05-1 \mu \mathrm{M})$. Similarly, pitavastatin was demonstrated to enhance the migration, proliferation and viability of human microvessel ECs at a low concentration $(0.01 \mu \mathrm{M})$ but inhibits these processes at a high concentration $(1 \mu \mathrm{M})$ (33). Furthermore, a recent study of ischemic retinopathies demonstrated a biphasic effect of simvastatin (34), in which low concentrations (0.01-0.1 $\mu \mathrm{M})$ significantly increased proliferation, migration, sprouting and tubulogenesis of retinal microvascular ECs but high concentrations (1-10 $\mu \mathrm{M})$ caused cell death and apoptosis. Our present data indicated that low dose simvastatin $(5-20 \mu \mathrm{M})$ promoted ATII cell proliferation and inhibited apoptosis, but the effects were completely opposite with high doses $(50-100 \mu \mathrm{M})$, similar to the above-mentioned published studies. Notably, the concentration of statins $(5-100 \mu \mathrm{M})$ used in our in vitro experiments was higher than that previously used in the other published studies $(0.01-10 \mu \mathrm{M})$. We think that the different cell type used in our experiments had a unique requirement for higher doses of simvastatin to elicit the observed effects. The MLE-12 cell line used in our study is a SV-40 virus immortalized mouse ATII cell line and the A549 ATII cell line originated from a lung adenocarcinoma tissue. There are obvious disparities between the pharmacokinetics of these two cell lines and that 
of primary cultured human ECs. This may be one explanation of why the statin concentrations used in this study were higher compared to those in the previous studies.

Different diseases or injuries have different physiopathological processes. Thus, statins may also elicit opposite effects under various disease conditions in the context of different organs. It has been proposed that statins do not simply inhibit or activate signaling pathways, but modulate them in order to alter cell fate. Among the numerous signaling pathways described as targets of statins, the PI3K/Akt pathway plays a crucial role in cell survival, apoptosis and proliferation (35). In conditions of tissue ischemia-reperfusion (I/R) injury $(25,26)$ or inflammatory disorders, such as airway hyperreactivity (21), renal glomerular podocyte injury (22) or traumatic brain injury (23), statins usually exert their protective effects by promoting cell proliferation and inhibiting apoptosis through the inhibition of upstream RhoA-kinase and the activation of downstream PI3K/Akt signaling. However, in conditions of cancer, statins appear to significantly decrease cancer cell proliferation, migration and metastasis via the inhibition of PI3K/Akt signaling (28-32). In fact, I/R or inflammation may induce apoptosis and inhibit proliferation via the downregulation of cell proliferation through any of the PI3K/Akt, ERK, or MAPK pathways and the upregulation of apoptosis through the Bcl-2, Bax and caspase families. However, cell survivalrelated pathways are usually upregulated in several types of solid cancers. Our data indicated that low concentrations of statins uniquely reverse H/R injured ATII cell function in vitro via a mevalonate pathway-dependent activation of PI3K/Akt signaling. Administration of PI3K inhibitor, wortmannin, reversed the protective effects of simvastatin by decreasing the levels of p-Akt and those of the downstream factors mTOR and p-P70 and by subsequently activating caspase-3. This modulated signaling cascade coincides with previous studies regarding the protective effect of statins on I/R. Consequently, we speculate that statins may maintain the balance of normal or abnormal cell fate by modulating the PI3K/Akt signaling pathway.

Finally, despite our notable findings, this study is subject to several experimental limitations. First, although MLE-12 and A549 cells have been used as in vitro models in previous ATII studies (36-38), these two cell lines cannot completely simulate the in vivo physiology of ATII cells. In future studies, primary cultured ATII cells may provide more direct evidence for the protective effect of statins. Second, in the in vivo experiments, the entire lung tissue specimen was used in the western blot analysis of PI3K/Akt signaling pathwayrelated proteins, which may have masked some subtle effects on the PI3K/Akt signaling pathway of ATII cells or detected changes that were induced by molecular interactions with non-ATII cells. In addition, statins were administered just prior to the onset of injury. It remains unknown whether administration of statins post-LIRI also has the same protective effect on ATII cells. More experiments are required to further identify this issue. Finally, we did not examine whether the repairing capacity of ATII cells was enhanced by simvastatin in the present study. Recently, the transforming growth factor $\beta 1$ (TGF- $\beta 1$ )/Smad pathway was demonstrated to contribute to the transdifferentiation process from ATII to ATI cells (39). It is possible that statins may also promote
ATII cell transdifferentiation into ATI cells via activation of the TGF- $\beta 1 /$ Smad pathway, which may be dependent on or independent of the mevalonate pathway. These questions will be addressed in our future studies.

In summary, to the best of our knowledge, we for the first time demonstrated that LIRI-induced injury of ATII cells may be reversed by relatively low dose simvastatin in vivo and in vitro. The protective effects of simvastatin were at least partially due to promotion of ATII cell proliferation and SP-C expression and inhibition of apoptosis through the activation of the PI3K/Akt signaling pathway in a mevalonate pathwaydependent manner. These findings provide new insights into the molecular mechanisms underlying the action of statins in LIRI. Administration of statins may provide a promising therapeutic strategy to rapidly regenerate epithelium in damaged lungs by endogenously increasing ATII cells.

\section{Acknowledgements}

This study was supported by grants from the Human Resource Summit Grant of Jiangsu Province (10-D-107 to Dr R.Y. and 10-D-105 to Dr F.J.) and the Natural Science Foundation of Jiangsu Province (BK2010589 to Dr L.X. and BK2011578 to Dr R.Y.).

\section{References}

1. Fujino N, Kubo H, Suzuki T, et al: Isolation of alveolar epithelial type II progenitor cells from adult human lungs. Lab Invest 91: 363-378, 2011.

2. Herzog EL, Brody AR, Colby TV, Mason R and Williams MC: Knowns and unknowns of the alveolus. Proc Am Thorac Soc 5: 778-782, 2008.

3. Wang D, Haviland DL, Burns AR, Zsigmond E and Wetsel RA: A pure population of lung alveolar epithelial type II cells derived from human embryonic stem cells. Proc Natl Acad Sci USA 104: 4449-4454, 2007.

4. Andreeva AV, Kutuzov MA and Voyno-Yasenetskaya TA: Regulation of surfactant secretion in alveolar type II cells. Am J Physiol Lung Cell Mol Physiol 293: L259-L271, 2007.

5. Mason RJ: Biology of alveolar type II cells. Respirology 11 (Suppl): S12-S15, 2006.

6. Neuringer IP and Randell SH: Stem cells and repair of lung injuries. Respir Res 5: 6, 2004.

7. Wang D, Morales JE, Calame DG, Alcorn JL and Wetsel RA: Transplantation of human embryonic stem cell-derived alveolar epithelial type II cells abrogates acute lung injury in mice. Mol Ther 18: 625-634, 2010.

8. Feng D, Zhang S, Hu Z, Fan F, Jiang F, Yin R and Xu L: Dynamic investigation of alveolar type II cell function in a long-term survival model of rat lung ischemia-reperfusion injury. Scand $\mathbf{J}$ Clin Lab Invest 70: 364-373, 2010.

9. Shanes JG, Minadeo KN, Moret A, Groner M and Tabaie SA: Statin therapy in heart failure: prognostic effects and potential mechanisms. Am Heart J 154: 617-623, 2007.

10. Makris GC, Geroulakos G, Makris MC, Mikhailidis DP and Falagas ME: The pleiotropic effects of statins and omega-3 fatty acids against sepsis: a new perspective. Expert Opin Investig Drugs 19: 809-814, 2010.

11. Veillard NR, Braunersreuther V, Arnaud C, Burger F, Pelli G, Steffens S and Mach F: Simvastatin modulates chemokine and chemokine receptor expression by geranylgeranyl isoprenoid pathway in human endothelial cells and macrophages. Atherosclerosis 188: 51-58, 2006.

12. Undas A, Celinska-Lowenhoff M, Kaczor M and Musial J: New nonlipid effects of statins and their clinical relevance in cardiovascular disease. Thromb Haemost 91: 1065-1077, 2004.

13. Naidu BV, Woolley SM, Farivar AS, Thomas R, Fraga C and Mulligan MS: Simvastatin ameliorates injury in an experimental model of lung ischemia-reperfusion. J Thorac Cardiovasc Surg 126: 482-489, 2003. 
14. Muller HC, Hellwig K, Rosseau S, et al: Simvastatin attenuates ventilator-induced lung injury in mice. Crit Care 14: R143, 2010.

15. Kor DJ, Iscimen R, Yilmaz M, Brown MJ, Brown DR and Gajic O: Statin administration did not influence the progression of lung injury or associated organ failures in a cohort of patients with acute lung injury. Intensive Care Med 35: 1039-1046, 2009.

16. Craig TR, Duffy MJ, Shyamsundar M, McDowell C, O'Kane CM, Elborn JS and McAuley DF: A randomized clinical trial of hydroxymethylglutaryl-coenzyme a reductase inhibition for acute lung injury (The HARP Study). Am J Respir Crit Care Med 183: 620-626, 2011

17. Shyamsundar M, Craig T, O'Kane C and McAuley D: Comment on 'Statin administration did not influence the progression of lung injury or associated organ failures in a cohort of patients with acute lung injury'. Intensive Care Med 35: 1494-1495, 2009.

18. Takahashi S, Nakamura H, Seki M, et al: Reversal of elastaseinduced pulmonary emphysema and promotion of alveolar epithelial cell proliferation by simvastatin in mice. Am J Physiol Lung Cell Mol Physiol 294: L882-L890, 2008.

19. Wolfrum S, Dendorfer A, Schutt M, et al: Simvastatin acutely reduces myocardial reperfusion injury in vivo by activating the phosphatidylinositide 3-kinase/Akt pathway. J Cardiovasc Pharmacol 44: 348-355, 2004.

20. Bell RM and Yellon DM: Atorvastatin, administered at the onset of reperfusion, and independent of lipid lowering, protects the myocardium by up-regulating a pro-survival pathway. J Am Coll Cardiol 41: 508-515, 2003.

21. Zeki AA, Franzi L, Last J and Kenyon NJ: Simvastatin inhibits airway hyperreactivity: implications for the mevalonate pathway and beyond. Am J Respir Crit Care Med 180: 731-740, 2009.

22. Bussolati B, Deregibus MC, Fonsato V, et al: Statins prevent oxidized LDL-induced injury of glomerular podocytes by activating the phosphatidylinositol 3-kinase/AKT-signaling pathway. J Am Soc Nephrol 16: 1936-1947, 2005.

23. Wu H, Lu D, Jiang H, et al: Simvastatin-mediated upregulation of VEGF and BDNF, activation of the PI3K/Akt pathway, and increase of neurogenesis are associated with therapeutic improvement after traumatic brain injury. J Neurotrauma 25: 130-139, 2008.

24. Eto M, Kozai T, Cosentino F, Joch H and Lüscher TF: Statin prevents tissue factor expression in human endothelial cells: role of Rho/Rho-kinase and Akt pathways. Circulation 105: 1756-1759, 2002.

25. Takeda N, Kondo M, Ito S, Ito Y, Shimokata K and Kume H: Role of RhoA inactivation in reduced cell proliferation of human airway smooth muscle by simvastatin. Am J Respir Cell Mol Biol 35: 722-729, 2006.

26. Taraseviciene-Stewart L, Scerbavicius R, Choe KH, et al: Simvastatin causes endothelial cell apoptosis and attenuates severe pulmonary hypertension. Am J Physiol Lung Cell Mol Physiol 291: L668-L676, 2006.
27. Weis M, Heeschen C, Glassford AJ and Cooke JP: Statins have biphasic effects on angiogenesis. Circulation 105: 739-745, 2002.

28. Hanai JI, Doro N, Sasaki AT, Kobayashi S, Cantley LC, Seth P and Sukhatme VP: Inhibition of lung cancer growth: ATP citrate lyase knockdown and statin treatment leads to dual blockade of mitogen-actiated protein kinase (MAPK) and phosphatidylinositol-3- kinase (PI3K)/AKT pathways. J Cell Physiol 227: 1709-1720, 2012

29. Khanzada UK, Pardo OE, Meier C, Downward J, Seckl MJ and Arcaro A: Potent inhibition of small-cell lung cancer cell growth by simvastatin reveals selective functions of Ras isoforms in growth factor signalling. Oncogene 25: 877-887, 2006.

30. Horiguchi A, Sumitomo M, Asakuma J, Asano T, Asano T and Hayakawa M: 3-Hydroxy-3-methylglutaryl-coenzyme A reductase inhibitor, fluvastatin, as a novel agent for prophylaxis of renal cancer metastasis. Clin Cancer Res 10: 8648-8655, 2004.

31. Sanli T, Liu C, Rashid A, et al: Lovastatin sensitizes lung cancer cells to ionizing radiation: modulation of molecular pathways of radioresistance and tumor suppression. J Thorac Oncol 6: 439-450, 2011.

32. Glynn SA, O'Sullivan D, Eustace AJ, Clynes M and O'Donovan N: The 3-hydroxy-3-methylglutaryl-coenzyme A reductase inhibitors, simvastatin, lovastatin and mevastatin inhibit proliferation and invasion of melanoma cells. BMC Cancer 8: 9, 2008.

33. Katsumoto M, Shingu T, Kuwashima R, Nakata A, Nomura S and Chayama K: Biphasic effect of HMG-CoA reductase inhibitor, pitavastatin, on vascular endothelial cells and angiogenesis. Circ J 69: 1547-1555, 2005.

34. Medina RJ, O'Neill CL, Devine AB, Gardiner TA and Stitt AW: The pleiotropic effects of simvastatin on retinal microvascular endothelium has important implications for ischaemic retinopathies. PLoS One 3: e2584, 2008.

35. Cantley LC: The phosphoinositide 3-kinase pathway. Science 296: 1655-1657, 2002.

36. Foster KA, Oster CG, Mayer MM, Avery ML and Audus KL: Characterization of the A549 cell line as a type II pulmonary epithelial cell model for drug metabolism. Exp Cell Res 243: 359-366, 1998.

37. Hoshino Y, Mio T, Nagai S, Miki H, Ito I and Izumi T: Cytotoxic effects of cigarette smoke extract on an alveolar type II cellderived cell line. Am J Physiol Lung Cell Mol Physiol 281: L509-L516, 2001.

38. Kannan S, Huang H, Seeger D, et al: Alveolar epithelial type II cells activate alveolar macrophages and mitigate $P$. Aeruginosa infection. PLoS One 4: e4891, 2009.

39. Bhaskaran M, Kolliputi N, Wang Y, Gou D, Chintagari NR and Liu L: Trans-differentiation of alveolar epithelial type II cells to type I cells involves autocrine signaling by transforming growth factor beta 1 through the Smad pathway. J Biol Chem 282: 3968-3976, 2007. 